정규논문 (Regular Paper)

방송공학회논문지 제18권 제3호, 2013년 5월 (JBE Vol. 18, No. 3, May 2013)

http://dx.doi.org/10.5909/JBE.2013.18.3.372

ISSN 2287-9137 (Online) ISSN 1226-7953 (Print)

\title{
$\mathrm{LBP}$ 와 HSV 컬러 히스토그램을 이용한 내용 기반 영상 검색
}

\author{
이 권a), 이 철 희 ${ }^{a \ddagger}$
}

\section{Content-based Image Retrieval using LBP and HSV Color Histogram}

\author{
Kwon Lee ${ }^{\text {a) }}$ and Chulhee Lee (1) $^{\ddagger}$ \\ 요 약
}

본 논문에서는 LBP와 HSV 컬러 히스토그램을 이용한 내용 기반 영상 검색 방법을 제안한다. 영상 검색 시스템에서는 텍스트가 아닌 사용자가 원하는 특정한 객체를 포함하는 영상을 질의로 입력하여 원하는 영상을 검색한다. 대부분의 연구에서는 색상, 질감, 모양 등과 같은 전역 특징 값을 이용하여 영상을 검색한다. 이러한 전역 특징 값들은 하늘이나 바닥과 같은 배경이 큰 부분을 차지하는 영상에서는 특징 값의 대부분이 배경에서 추출되어 영상 검색의 성능 저하를 초래한다. 이러한 문제를 해결하기 위해, 컬러를 이용하여 영상의 배경 을 고속으로 검출하고 배경의 영향을 줄여 관심 객체의 특징을 강조한다. 제안된 방법에서는 특징 값으로 HSV 컬러 히스토그램과 Local Binary Patterns을 사용한다. 또한, 색의 경계 부분의 패턴을 추출하기 위해 양자화 된 Hue 채널에서 Local Binary Patterns을 추출한다. 제안된 알고리즘의 성능 검증하기 위해, Corel 1000 database를 이용하여 실험한 결과 $82 \%$ 이상의 높은 검색 정확도를 나타내었다.

\section{Abstract}

In this paper, we proposed a content-based image retrieval algorithm using local binary patterns and HSV color histogram. Images are retrieved using image input in image retrieval system. Many researches are based on global feature distribution such as color, texture and shape. These techniques decrease the retrieval performance in images which contained background the large amount of image. To overcome this drawback, the proposed method extract background fast and emphasize the feature of object by shrinking the background. The proposed method uses HSV color histogram and Local Binary Patterns. We also extract the Local Binary Patterns in quantized Hue domain. Experimental results show that the proposed method $82 \%$ precision using Corel 1000 database.

Keyword : Image Retrieval, Background Extraction, Local Binary Patterns, HSV Color, Low Complexity

a) 연세대학교 전기전자공학과 (School of Electrical \& Electronic Engineering at Yonsei University)

‡ Corresponding Author : 이철희(Chulhee Lee) E-mail: chulhee@yonsei.ac.kr Tel: +82-2-2123-2779

※ 이 논문은 정부(교육과학기술부)의 재원으로 한국연구재단의 특정기초 연구 지원을 받아 수행된 연구임(No.2008-0052335).

Manuscript received February 21, 2013 Revised April 9, 2013 Accepted April 26, 2013

\section{I. 서 론}

인터넷, 모바일 통신과 같은 다양한 통신망의 발전과 더 불어 웹 카메라, 디지털 카메라, 모바일 카메라 등의 장비가 대중화되면서 멀티미디어 정보의 양이 급격하게 증가하고 있다. 특히 사진이나 비디오와 같은 디지털 영상 데이터들 이 증가하면서 방대해진 영상 정보 속에서 사용자가 원하 
는 정보를 획득하기 위한 효율적인 영상 검색 연구에 대한 관심이 높아지고 있다 ${ }^{[1]}$. 방대한 영상 데이터들에서 원하는 정보를 검색하기 위해서는 고속의 영상 검색은 중요한 기 술로 부각되고 있다. 영상 검색은 크게 색인어를 이용하는 텍스트 기반 영상 검색 방법과 영상의 특징을 이용하는 내 용기반 영상 검색 방법 (Content-Based Image Retrieval)이 있으며, 내용기반 영상검색은 주로 색상, 질감, 모양 등의 여러 특징들을 추출한다 ${ }^{[2]}$.

색상 특징은 질감이나 모양 특징에 비해 추출이 쉽고 높 은 성능으로 인해 영상 검색에서 널리 사용되고 있다. 색상 특징은 영상의 크기나 각도 변화 등에 불변하는 특성이 있 다. Swain과 Ballard는 컬러 히스토그램을 기반으로 한 컬 러 인덱싱을 제안하였다 ${ }^{[3]}$. 컬러 히스토그램은 공간정보의 생략으로 인한 판별력의 한계를 가지고 있다. 이러한 한계 를 극복하기 위해 컬러 영역의 공간적 관계를 이용하는 컬 러 모멘트가 제안되었다 ${ }^{[4]}$. Singh와 Hemachandran은 컬러 히스토그램과 컬러 모멘트를 조합한 영상 검색 방법을 제 안하였다 ${ }^{[5]}$. 컬러를 기반으로 한 방법들은 연산이 간단하고 대체적으로 우수한 영상 검색 성능을 나타내지만, 비슷한 배경색을 갖는 다른 범주의 영상을 검색하는 경우가 많다. 이러한 문제를 해결하기 위해 자연 영상에서 중요한 특징 인 질감 특징과 같은 추가적인 특징을 영상 검색에 사용한 다. Moghaddam은 Gabor 웨이블릿 correlogram을 이용한 영상 검색 방법을 제안하였다 ${ }^{[6]}$. Gabor 웨이블릿 correlogram은 영상의 회전변화에 강인한 특징이 있다. Manjunath 와 $\mathrm{Ma}$ 는 질감 특징 추출에 많이 이용되는 Gabor 특징을 이용하여 영상 검색을 제안하였다 ${ }^{[7]}$. Murala는 수직, 수평 방향의 기울기 방향을 이용하여 지역 패턴을 부호화하는 Local tetra patterns을 제안하였다 ${ }^{[8]}$. 기존의 LBP와 LTP는 주변 화소 값을 참조 화소 값과 비교하여 패턴을 부호화하 는 반면, Local tetra patterns은 1차 미분 값으로 구해진 기 울기 방향을 기반으로 하여 패턴을 부호화한다. Singh는 컬 러 모멘트와 Gabor 특징을 결합한 영상 검색 방법을 제안 하였다 ${ }^{[9]}$.

대부분의 내용기반 영상 검색에서는 색상, 질감, 모양 등 의 영상 전체에서 전역적인 특징을 추출한다. 전역적인 특 징들은 하늘이나 바닥이 영상의 많은 부분을 차지하는 영

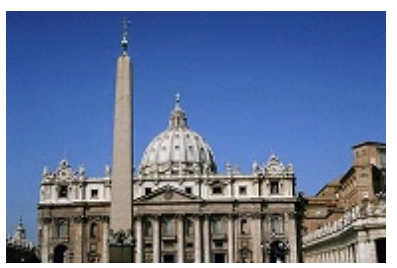

(a)

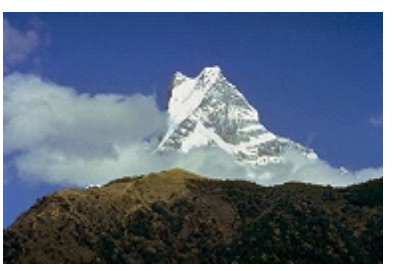

(c)

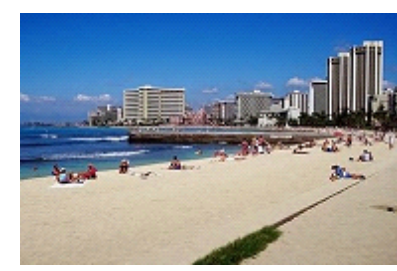

(b)

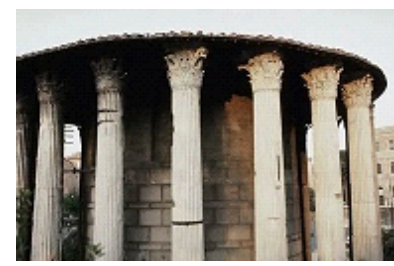

(d)
그림 1 . 컬러 기반 전역 특징을 이용한 영상 검색 (a) Query 영상, (b), (c) 상위 랭크 영상, (d) 하위 랭크 영상

Fig. 1. Image retrieval using global feature based on color (a) Query image, (b), (c) high rank image, (d) low rank image

상에서 좋은 성능을 내지 못한다. 그림 1은 대표적인 전역 적인 특징인 컬러 히스토그램을 이용한 영상 검색 결과이 다. H, S, V 채널을 각각 16 개, 4 개, 4 개의 빈을 사용하여 컬러 히스토그램을 영상 검색의 특징으로 사용하였으며, 그림 1의 영상들은 Corel 1000 database에 속한 이미지이 다. 그림 1. (a)의 query 영상을 이용하여 검색한 결과 같은 Building 그룹에 속한 (d) 영상보다 다른 그룹에 속한 (b), (c) 영상이 더 높은 랭크를 나타내고 있다. 영상의 많은 부 분을 차지하는 하늘 배경이 큰 영향을 미친 결과이다. 이러 한 문제를 해결하기 위해 영상의 배경을 고속으로 검출하 고 배경의 영향을 줄여 관심 객체의 특징을 강조한다. 제안 된 방법에서는 색상 특징으로 HSV 컬러 히스토그램을 추 출하며, 질감 특징으로 Local Binary Patterns (LBP)를 추출 한다. 또한 색상의 경계 부분의 패턴을 추출하기 위해서 양 자화 된 $\mathrm{Hue}$ 채널에서 $\mathrm{LBP}$ 를 추출하고 특징들을 결합하여 영상을 검색한다. 제안된 방법은 배경을 검출하여 관심 객 체의 특징을 강조하기 때문에 배경이 많은 부분을 차지하 는 이미지에서 높은 성능을 보였다. 또한 배경 검출 시, 기 존에 많이 사용되는 영역 분할 기술 [11]이 아닌 컬러 기반 의 고속 배경 검출 알고리즘을 적용하여 빠르게 검색이 가 능하다. 
본 논문의 구성은 다음과 같다. ㅍㅈ절에서 제안된 방법에 대해 설명하고 $\mathrm{II}$ 절에서 실험결과를 보여준다. $\mathrm{V}$ 절에서는 결론을 기술한다.

\section{II. 제안하는 알고리즘}

그림 2는 제안된 알고리즘의 순서도를 나타낸다. Query 영상이 입력으로 들어오면 고속 배경 검출 알고리즘을 적 용한다. 검출된 배경을 이용하여 배경의 영향을 줄여 특징 을 추출한다. 추출된 특징은 데이터베이스에 있는 특징들 과 비교하여 상위 랭크에 속한 이미지를 출력한다. 데이터 베이스에 저장된 특징들은 Query 이미지의 특징 추출 과정 과 동일한 과정을 거쳐 추출되어 저장된다.

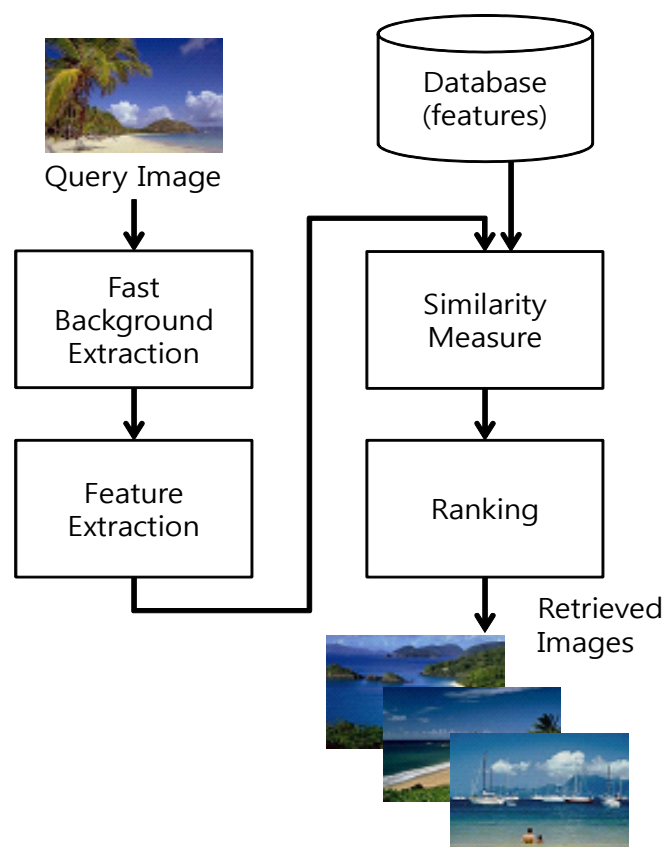

그림 2. 제안된 알고리즘의 순서도

Fig. 2. Block diagram of the proposed method

\section{HSV color 기반 고속 배경 검출}

$\mathrm{RGB}$ 컬러 공간은 인간 시각 체계에 균일하게 인지되지 않는다. 즉, 동일한 거리에 떨어져 위치한 색의 강도는 인간
의 시각에 동일한 정도의 색 차이로 인지되지 않는다. 이에 반해 HSV 컬러 공간은 인간 시각 체계에 근사적으로 균일 하게 인지된다. HSV (Hue, Saturation, Value) 컬러는 RGB 컬러를 다음과 같은 비선형 변환을 통해 얻어진다.

$$
\begin{aligned}
& H=\cos ^{-1} \frac{\frac{1}{2}[(R-G)+(R-B)]}{\sqrt{(R-G)^{2}+(R-B)(G-B)}} \\
& S=1-\frac{3[\min (R, G, B)]}{R+G+B} \\
& V=\left(\frac{R+G+B}{3}\right)
\end{aligned}
$$

여기서 $\mathrm{R}, \mathrm{G}, \mathrm{B}$ 는 각각 $\mathrm{RGB}$ 채널에서의 화소값을 나타 내며, $\mathrm{H}, \mathrm{S}, \mathrm{V}$ 는 변환된 $\mathrm{HSV}$ 채널의 화소값을 나타낸다. $\mathrm{H}$ 는 0 도에서 360 도 사이의 값을 가지며, $\mathrm{S}$ 와 $\mathrm{V}$ 는 0 에서 1 사이의 값을 갖는다.

영상의 배경은 대부분 그림 1 과 같이 한 가지 색으로 이 루어져 있다. 이는 인간이 하나의 색으로 인지할 뿐이며 실 제로는 명도와 채도가 약간씩 다른 여러 가지 색으로 이루 어져 있다. 영상에서 인간이 인지하는 배경을 하나의 씩으 로 표현하여 해당 색을 갖는 화소를 추출하고 이를 하나의 객체로 인식하여 배경을 검출하여야 한다. 본 논문에서는 배경을 추출하기 위해서 먼저 Hue 채널을 16 개의 빈으로 균등하게 분류한다. 입력 이미지를 그림 3 과 같이 Hue의 값 범위에 따라서 해당 범위 값을 갖는 색을 추출하여 마스 크 영상을 생성한다. 추출된 화소들을 하나의 객체로 인식 하기 위해 이웃한 화소들과 연결된 화소들을 함께 모아준 다. 추출된 화소들을 모은 영상에 Connected Component Analysis $(\mathrm{CCA})$ 를 적용하여 연결된 영역을 추출하고 추출 된 영역 중 가장 큰 영역을 선택한다. 영상의 배경은 가장자 리에 위치한다. 영상의 중심에 있는 큰 객체는 배경이 아닌 중요한 관심 객체이다. 이러한 관찰을 통해 추출된 가장 큰 영역 중에서 가장자리에 속하지 않은 영역을 제거한다. 각 각의 이미지에 남은 영역을 하나의 이미지로 병합하여 하 나의 배경 마스크를 생성한다. 그림 3 은 배경 검출 알고리 즘을 설명한다. Hue 채널을 16 개의 빈으로 균등하게 양자 화 하여 16 개의 색으로 이미지를 분리한다 (그림 $3(\mathrm{~b})$ ). 비 


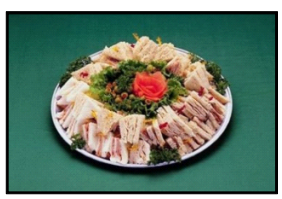

Input Image

(a)
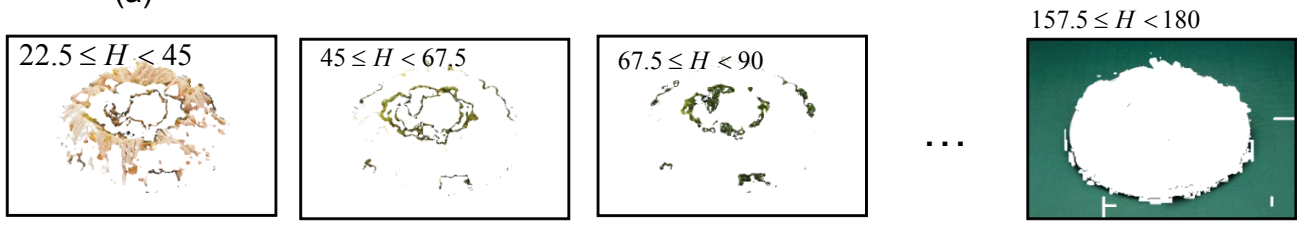

(b)
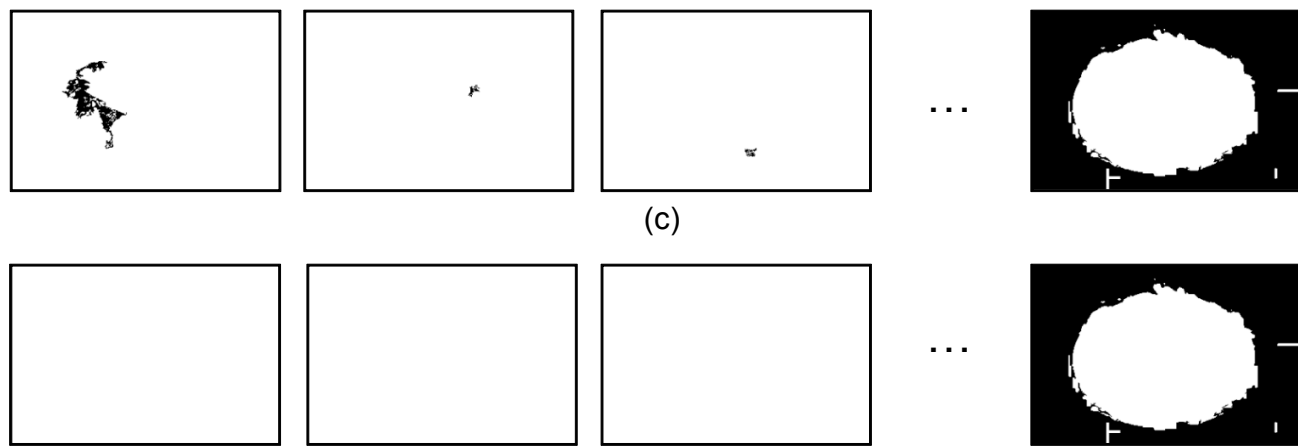

(c)

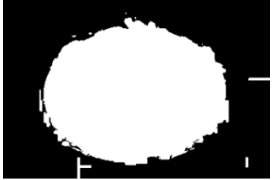

(e)

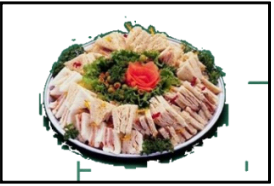

(f)

그림 3. 제안된 배경 검출 알고리즘

Fig. 3. The proposed background extraction algorithm

슷한 색을 갖는 음식과 가장자리에 있는 식탁보가 각각 다 른 색으로 분리된다. 여기에 $\mathrm{CCA}$ 를 각각의 분리된 이미지 에 적용하여 인접한 화소들을 하나의 객체로 묶어 준다. 여 러 개의 객체가 생성될 가능성이 있으며 이때 가장 큰 객체 를 선택한다 (그림 3(c)). 선택된 객체 중 가장 자리에 속하 지 않은 객체를 제거하면 그림 3(d)와 같이 영상의 중심에 위치한 음식 영역이 제거된다. 그림 3(d)에서 생성된 각각 의 이미지를 병합해주면 그림 3(e)와 같이 배경 마스크가 만들어지고 그림 3(f)는 배경을 제거하고 남은 모습을 보여 준다.

다음 단계로 검출된 배경 마스크를 이용하여 HSV 컬러

히스토그램을 생성한다. 배경에 의한 영향을 줄이기 위해 히스토그램 생성 시 배경 영역에서는 화소 수를 줄여서 집 계한다. 컬러 빈 $v$ 에서 배경 마스크 영역에서는 컬러 히스 토그램 $H(v)$ 를 $a(<1)$ 개로 집계하고 배경 마스크 이외 의 영역에서는 컬러 히스토그램 $H(v)$ 를 원래대로 1 개로 집계를 한다. 본 논문에서는 Hue 채널을 16 개의 빈, $\mathrm{S}$ 와 $\mathrm{V}$ 는 4 개의 빈을 사용하였으며, $a=0.5$ 는 실험적으로 얻 어진 값을 사용한다.

$$
\begin{aligned}
& \text { if }(\text { mask_region }(i)) H(v)+=a \\
& \text { else } H(v)+=1
\end{aligned}
$$




\section{Local Binary Patterns (LBP)}

영상의 질감 특징으로 LBP 특징 히스토그램을 사용한다. LBP 코드는 중심 화소 값을 주변 화소 값과 비교하여 할당 한다. 주변 화소의 값이 중심 화소 값보다 크면 1 을 할당하 고, 작으면 0 을 할당한다. 그림 4 와 같은 $3 \times 3$ 블록 구조를 사용하였다. 주변 화소들은 중심 화소 값과 비교하여 다음 과 같이 코드가 할당된다.

$$
s\left(g_{0}, g_{i}\right)=\left\{\begin{array}{l}
1, g_{i} \geq g_{0} \\
0, g_{i}<g_{0}
\end{array}, 1 \leq i \leq 8\right.
$$

이웃 화소들에 할당된 8-bit를 다음 식을 이용하여 10 진 수로 변환해주고 변환된 값을 중심 화소의 LBP 값으로 할 당한다.

$$
\operatorname{LBP}\left(g_{0}\right)=\sum_{i=1}^{8} s\left(g_{0}, g_{i}\right) \cdot 2^{i-1}
$$

모든 화소들은 이러한 연산을 통해 LBP 값을 할당 받고 LBP값의 히스토그램을 생성하여 특징으로 사용한다.

\begin{tabular}{|l|l|l|}
\hline$g_{1}$ & $g_{2}$ & $g_{3}$ \\
\hline$g_{4}$ & $g_{0}$ & $g_{5}$ \\
\hline$g_{6}$ & $g_{7}$ & $g_{8}$ \\
\hline
\end{tabular}

그림 4. $3 \times 3$ 블록 구조

Fig. 4. $3 \times 3$ neighboring structure

\section{Hue-LBP}

LBP 특징은 영상 검색에서 좋은 성능을 내지만 저주파 영역에서도 패턴을 발생시킨다. 그림 5. (a)의 하늘 영역과 그림 5. (b)의 버스의 옆면은 영상의 저주파 영역으로 인간 의 시각에는 인지되지 않는 패턴이 있다. 이러한 패턴들은 LBP 이미지에서 그림 5. (c)와 그림 5. (d)처럼 미세한 패턴 들이 생성된다. 인간 시각에 인지되지 않는 미세한 패턴을
없애고 색의 경계 부분의 패턴을 특징으로 사용하기 위해 서 제안된 알고리즘에서는 16 레벨로 양자화 된 Hue 채널 에 LBP를 적용하였다. 그림 5. (e)와 그림 5. (f)는 Hue 채널 에 LBP를 적용한 결과이다 (Hue-LBP 이미지). 그림에서 나타나듯이 동일한 Hue 값을 갖는 저주파 영역에서는 패턴 을 생성하지 않으며, 색의 경계 부분에 LBP 패턴을 생성한 다. Hue-LBP 이미지로부터 히스토그램을 생성하여 특징으 로 사용한다.

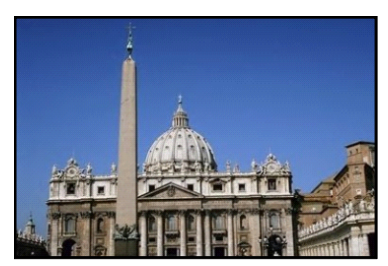

(a)

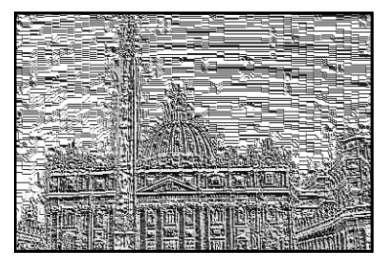

(c)

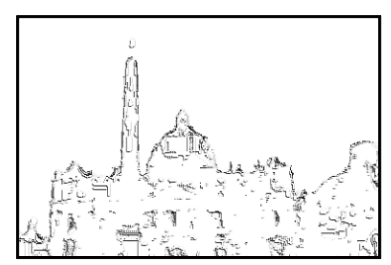

(e)

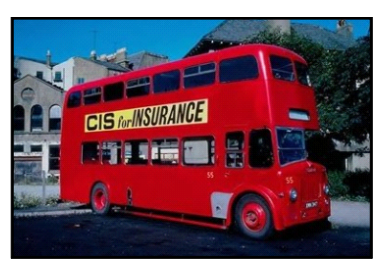

(b)

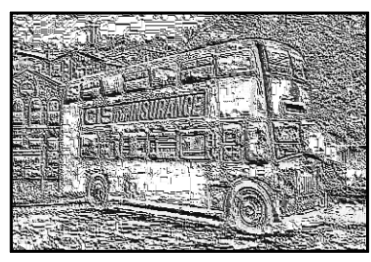

(d)

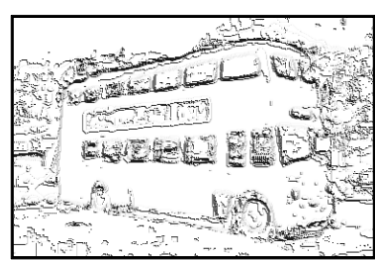

(f)
그림 5 . LBP 이미지와 Hue-LBP 이미지 (a) 원본 이미지, (b) LBP 이미지, (c) Hue-LBP 이미지

Fig. 5. LBP image and Hue LBP 이미지 (a) original image, (b) LBP image, (c) Hue-LBP image

\section{Similarity measure}

제안된 방법에서는 HSV 컬러 히스토그램, LBP 히스토 그램, Hue-LBP 히스토그램을 특징으로 사용한다. 배경 컬 러의 영향을 줄이기 위해서 제안된 배경 추출 방법을 이용 
하여 배경을 분리한 후 HSV 컬러 히스토그램을 추출한다. LBP 히스토그램과 Hue-LBP 히스토그램은 영상의 전체 영 역에서 추출된다. 특징의 유사도를 측정하기 위해 D1 similarity distance와 correlation을 사용한다. D1 similarity distance는 다음과 같다.

$$
D(D, Q)=\sum_{i=1}^{N}\left|\frac{f_{D, i}-f_{Q, i}}{1+f_{D, i}-f_{Q, i}}\right|
$$

여기서 $D$ 는 데이터 베이스의 이미지, $Q$ 는 query 이미 지, $N$ 은 특징 벡터의 길이, $f_{D, i}$ 는 데이터 베이스 이미지의 $i$ 번째 특징 값, $f_{Q, i}$ 는 query 이미지의 $i$ 번재 특징 값을 나타낸다. Correlation은 다음과 같이 구해진다.

$$
C(D, Q)=\frac{E\left[\left(f_{D}-\mu_{f_{D}}\right)\left(f_{Q}-\mu_{f_{Q}}\right)\right]}{\sigma_{f_{D}} \sigma_{f_{Q}}}
$$

여기서 $\mu_{f_{D}}$ 는 데이터 베이스 이미지 $D$ 의 특징 벡터의 평균, $\mu_{f_{Q}}$ 는 query 이미지 $Q$ 의 특징 벡터의 평균, $\sigma_{f_{D}}, \sigma_{f_{Q}}$ 는 데이터 베이스 이미지의 특징 벡터와 query 이미지의 특 징 벡터의 표준편차를 나타낸다.

본 논문에서, $\mathrm{HSV}$ 컬러 히스토그램과 $\mathrm{LBP}$ 히스토그램 은 D1 similarity distance를 사용하였으며, Hue-LBP 히스 토그램의 경우 대부분의 특징이 평활 영역을 나타내며 $(11111111)_{2}$ 패턴이 대부분을 차지하여 D1 similarity distance를 사용할 경우 특징간의 변별력이 사라진다. Hue-LBP 히스토그램은 특징 벡터에서 $(11111111)_{2}$ 패턴 을 제외하고 correlation을 사용하여 유사도를 측정하였다. 각각의 특징 벡터의 유사도를 $S_{1}, S_{2}, S_{3}$ 라 할 때, 영상의 최종 유사도 점수 $d$ 는 다음과 같이 구해진다.

$$
d=w_{1} \cdot S_{1}+w_{2} \cdot S_{2}+w_{3} \cdot S_{3}
$$

$w_{1}, w_{2}, w_{3}$ 은 유사도 점수 $S_{1}, S_{2}, S_{3}$ 의 가중치이다. 본 논문에서는 실험적으로 얻어진 $w_{1}=w_{2}=w_{3}=1 / 3$ 을 이용하였다.

\section{III. 실험 결과}

제안된 방법의 성능을 검증하기 위해 Corel 1000 database $^{[10]}$ 를 이용하여 실험하였다. Corel 1000 database는 10 개의 그룹에 각각 100 장의 이미지로 구성되어 있다. 10 개 의 그룹은 Africa, Beaches, Buildings, Buses, Dinosaurs, Elephants, Flowers, Hores, Mountains, Food로 다양한 이 미지를 포함하고 있다. 그림 6 은 고속 배경 검출 알고리즘 을 수행한 결과이다. 음식의 주변 배경과, 건물의 하늘, 버 스 이미지의 하늘과 바닥이 검출 된 것을 확인할 수 있다.

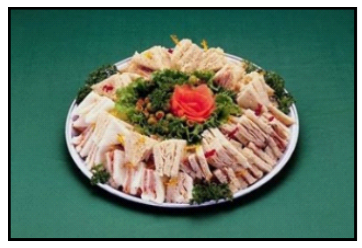

(a)

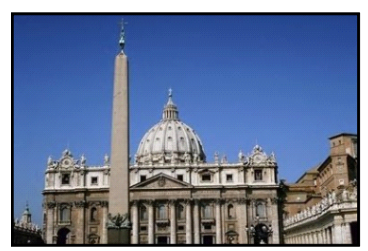

(c)

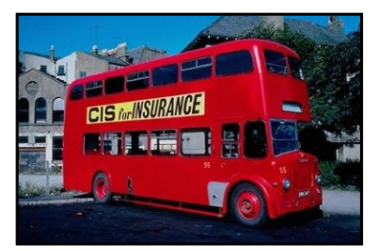

(e)

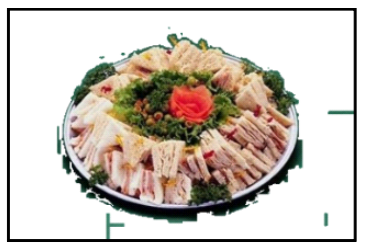

(b)

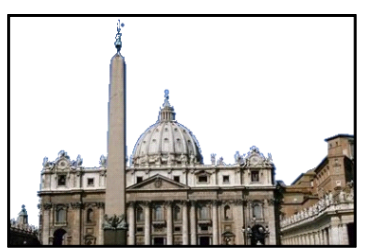

(d)

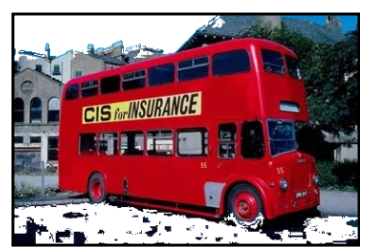

(f)
그림 6. 고속 배경 검출 결과 (a), (c), (e) 원본 이미지, (b), (d), (f) 배경 검출 이미지

Fig. 6. Fast background extraction results (a), (c), (e) original image, (b), (d), (f) result image

제안된 알고리즘의 성능은 정확도 (precision)을 이용하 였다. 정확도는 다음과 같이 구해진다.

$$
\text { Precision }=\frac{\text { No.of Relevant Images Retrieved }}{\text { Total No.of ImagesRetrieved }}
$$


Total No.of ImagesRetrieved는 검색된 전체 이미지 수를 나타내며 query로 사용된 이미지 수와 검색 결과로 출력되는 상위 랭크 이미지 수의 곱으로 나타난다. No. of Relevant Images Retrieved는 검색된 이미지 중에 서 같은 그룹에 속한 이미지의 수를 나타내며, 각각의 query 이미지를 이용하여 상위 랭크 이미지들 중에 같은 그 룹에 속한 이미지 수들의 합으로 나타난다. 하나의 query 이미지를 입력으로 주어졌을 때, 검색된 이미지가 query 이 미지와 같은 그룹에 있는 경우가 정확히 검색된 것으로 한 다. 1000 개의 이미지 중 하나의 이미지를 query 이미지로 선택하고 1000 개의 데이터베이스 중에서 상위에 랭크된 이 미지를 출력한다. 표 1 은 상위 10 개의 이미지를 출력할 때 평균 정확도 결과를 보여준다. 기존의 방법들과 비교하여 $7 \%$ 이상의 성능 향상을 보였으며, 특히 하늘 배경을 포함 하는 Buildings 그룹과 Mountains 그룹에서 눈에 띄는 성능 향상을 보였다. 제안된 고속 배경 검출 알고리즘을 이용한 특징 검출 방법의 우수성을 보여준다.

\section{표 1. 영상 검색 평균 정확도}

Table 1. Average precision for image retrieval

\begin{tabular}{|c|c|c|c|c|}
\hline Category & LBP & HSV & LTP[8] & Proposed \\
\hline Africans & 61.8 & 75.5 & 68.5 & 87.3 \\
\hline Beaches & 55.4 & 41.6 & 62.4 & 59.7 \\
\hline Buildings & 65.4 & 65.1 & 74.0 & 80.4 \\
\hline Buses & 96.7 & 87.3 & 97.5 & 95.1 \\
\hline Dinosaurs & 98.4 & 100.0 & 97.0 & 99.7 \\
\hline Elephants & 46.3 & 62.0 & 60.1 & 73.8 \\
\hline Flowers & 92.2 & 77.5 & 90.2 & 95.0 \\
\hline Horses & 76.7 & 93.9 & 79.2 & 99.2 \\
\hline Mountains & 41.9 & 32.0 & 41.3 & 52.1 \\
\hline Food & 68.6 & 78.4 & 88.3 & 86.6 \\
\hline Total & 70.3 & 71.33 & 75.9 & 82.9 \\
\hline
\end{tabular}

그림 7 은 검색하는 이미지의 수를 10 에서 100 으로 늘려 서 실험한 결과를 보여준다. 여기서 검색하는 이미지의 수 만큼의 상위 랭크 이미지들 중에서 query 이미지와 같은 그 룹에 속한 비율로 정확도를 측정한다. 예를 들어 한 개의 query 이미지로 20 개의 이미지를 검색했을 때, 상위 20 개의 검색 이미지들 중에 query 이미지와 같은 그룹에 속한 이미 지가 19 개일 경우 $95 \%$ 의 정확도를 나타낸다. 그림 7 에서 보는 바와 같이 제안된 방법은 검색 이미지의 수를 늘려도 향상된 성능을 나타냄을 알 수 있다.

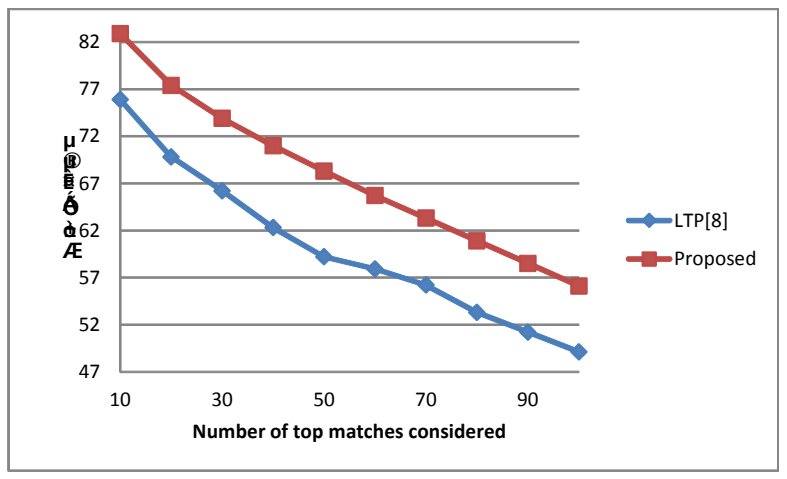

그림 7. 평균 정확도 비교

Fig. 7. Comparison of the average precision

표 2는 제안된 방법의 연산 속도를 나타낸다. Query 이미 지에서 배경을 검출하고 검출된 배경을 이용하여 세 가지 특징 (HSV histogram, LBP histogram, Hue-LBP histogram)을 추출한다. 추출된 특징을 데이터베이스에 사전에 추출된 특징들과 비교하여 최종 순위를 출력한다. 배경 검 출 알고리즘을 추가하여도 영상 검색에 걸리는 시간은 0.022 초로 빠르게 검색함을 보여준다. 영상 검색의 매칭 점 수의 순위는 heap sorting을 사용하였다.

표 2. 제안된 방법의 연산 속도

Table 2. Processing time of the proposed method

\begin{tabular}{|c|c|c|c|c|c|c|c|}
\hline & $\begin{array}{c}\text { Background } \\
\text { extraction }\end{array}$ & $\begin{array}{c}\text { HSV } \\
\text { histogram } \\
\text { extraction }\end{array}$ & $\begin{array}{c}\text { LBP } \\
\text { histogram } \\
\text { extraction }\end{array}$ & $\begin{array}{c}\text { Hue-LBP } \\
\text { histogram } \\
\text { extraction }\end{array}$ & $\begin{array}{c}\text { Feature } \\
\text { matching }\end{array}$ & Racking & Total \\
\hline $\begin{array}{c}\text { Processing } \\
\text { time(s) }\end{array}$ & 0.007 & 0.003 & 0.003 & 0.003 & 0.004 & 0.002 & 0.022 \\
\hline
\end{tabular}




\section{IV. 결 론}

영상 검색은 배경이 아닌 관심 객체의 특징을 이용하여 이루어 져야 한다. 기존의 전역적인 특징들은 영상의 많은 부분을 차지하는 배경의 영향으로 인해 성능이 떨어졌다. 제안된 방법에서는 영역 분할이 아닌 HSV 색상 정보를 이 용한 고속 배경 검출을 이용하여 배경을 검출하고 검출된 배경의 영향을 줄여 관심 객체의 특징을 강조하였다. Corel 1000 database를 이용한 성능 검증 결과 $82 \%$ 이상의 높은 정확도를 나타냈다.

\section{참 고 문 헌}

[1] S. Chang, J. Smith, M. Beigi and A. Benitez, "Visual Information Retrieval from Large Distributed Online Repositories," Communications of the ACM, Vol. 40, No. 12, pp. 63-71, Dec. 1997.

[2] Y. Rui, T. Huang, and S. Chang, "Image retrieval: current techniques, promising directions and open issues," Journal of Visual Communication and Image Representation, Vol. 10, No. 4, pp. 39-62, March, 1999.

[3] M.Z. Swain, and D.H. Ballard, "Color Indexing," International Journal of Computer Vision, Vol. 7, No. 1, pp. 11-32, Nov. 1991.
[4] M. Stricker, and M. Orengo, "Similarity of color images," In SPIE Conference on Storage and Retrieval for Image and Video Databases, Vol. 2420, pp. 381-392, 1995.

[5] S. M. Singh and K. Hemachndran, "Image retrieval based on the combination of color histogram and color moment," International Journal of Computer Applications, Vol. 58, No. 3, pp. 27-34, Nov. 2012.

[6] H. A. Moghaddam and M. S. Tarzjan, "Gabor wavelet correlogram algorithm for image indexing and retrieval," in Proc. ICPR, Vol. 2, pp. 925-928, 2006.

[7] B.S. Manjunath, and W.Y. Ma, "Texture Features for browsing and retrieval of image data," IEEE Transactions on Pattern Analysis and Machine Intelligence, Vol. 18, No. 8, pp. 837-842, 1996.

[8] S. Murala, R. P. Maheshwari and R. Balasubramanian, "Local Tetra Patterns: A New Feature Descriptor for Content-Based Image Retrieval," IEEE Transactions on Image Processing, Vol. 21, No. 5, pp. 2874-2886, May, 2012.

[9] S. M. Singh and K. Hemachndran, "Content-Based Image Retrieval using Color Moment and Gabor Texture Feature," International Journal of Computer Science, Vol. 9, No. 1, pp. 299-309, Sep. 2012.

[10] J. Z. Wang, J. Li and G. Wiederhold, "SIMPLIcity: Semantics-sensitive Integrated Matching for Picture LIbraries," IEEE Trans. on Pattern Analysis and Machine Intelligence, Vol 23, No.9, pp. 947-963, Sep. 2001.

[11] M. Fang, Y. Kuan, C. Kuo, and C. Hsieh, "Effective image retrieval techniques based on novel salient region segmentation and relevance feedback," Multimedia Tools and Applications, vol. 57, no. 3, pp. 501-525, April, 2012.

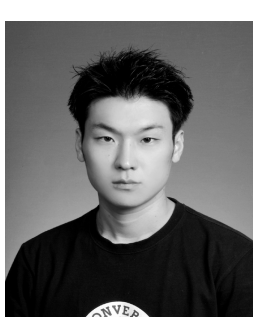

\section{이 권}

- 2006년 2월 : 연세대학교 전기전자공학과 졸업 (학사)

- 2008년 2월 : 연세대학교 전기전자공학과 졸업 (석사)

- 2008년 현재 : 연세대학교 전기전자공학과 박사과정

- 주관심분야 : 영상 신호처리/압축, 이미지 및 비디오 화질평가, 패턴인식

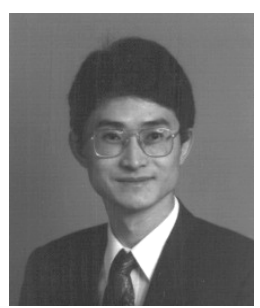

이 철 희

- 1984년 2월 : 서울대학교 전자공학과 졸업 (학사)

- 1986년 2월 : 서울대학교 전자공학과 졸업 (석사)

- 1986년 1987년 : Technical University of Denmark (DTH), Denmark

- 1992년 12월 : Purdue University Electrical Engineering Ph.D

- 1993년 1996년 : National Institutes of Health(NIH), Maryland USA

- 1996년 현재 : 연세대학교 전기전자공학과 교수

- 주관심분야 : 영상 신호처리, 비디오 화질평가, 패턴인식 및 Machine Vision 